Perspective

\title{
Toward Sociocultural Indicators of Sustainable Healthy Diets
}

\author{
Jill Nicholls ${ }^{1, *}$ and Adam Drewnowski ${ }^{2}$ \\ 1 Food Context LLC, Indianapolis, IN 46228, USA \\ 2 Center for Public Health Nutrition, University of Washington, Seattle, WA 98195, USA; adamdrew@uw.edu \\ * Correspondence: jill.nicholls20@gmail.com
}

check for

updates

Citation: Nicholls, J.; Drewnowski, A. Toward Sociocultural Indicators of Sustainable Healthy Diets. Sustainability 2021, 13, 7226. https:// doi.org/10.3390/su13137226

Academic Editor: Djin Gie Liem

Received: 2 June 2021

Accepted: 22 June 2021

Published: 28 June 2021

Publisher's Note: MDPI stays neutral with regard to jurisdictional claims in published maps and institutional affiliations.

Copyright: (C) 2021 by the authors. Licensee MDPI, Basel, Switzerland. This article is an open access article distributed under the terms and conditions of the Creative Commons Attribution (CC BY) license (https:/ / creativecommons.org/licenses/by/ $4.0 /)$.

\begin{abstract}
Balancing the social, economic and environmental priorities for public health is at the core of the United Nations (UN) approaches to sustainable development, including the Sustainable Development Goals (SDGs). The four dimensions of sustainable diets are often presented as health, society, economics, and the environment. Although sustainable diet research has focused on health and the environment, the social and economic dimensions of sustainable diets and food systems should not be forgotten. Some research priorities and sociocultural indicators for sustainable healthy diets and food systems are outlined in this report. The present goal is to improve integration of the social dimension into research on food and nutrition security.
\end{abstract}

Keywords: sustainable diets; sustainable food systems; social dimension; economic dimension; sociocultural indicator; sustainability indicator; food security and nutrition

\section{Introduction}

The concept of sustainability is multi-dimensional, yet research on sustainable diets has focused primarily on health and environmental outcomes [1,2]. By contrast, the social and economic dimensions of sustainability have been under-represented in research on dietary patterns [2,3], food systems [4-6], sustainable agriculture [7,8], and social sustainability [9-11]. As definitions of healthy diets from sustainable food systems continue to evolve, there will be opportunities to better integrate the social dimension into research agendas. Needed are food system solutions that provide healthy, affordable diets with positive, equitable socioeconomic outcomes along food supply chains and with low impacts on the environment. The paper aims to better-define the social indicators of sustainable healthy diets and place them alongside the health, economic, and environmental metrics and measures.

The paper provides a perspective about the importance of considering all dimensions of sustainability when assessing sustainable healthy diets; describes the gap in research on the social dimension of sustainable diets and sustainable food systems; and presents ways that researchers in the nutrition community can integrate the social dimension of sustainability into their work.

\section{Background: The Three Dimensions of Sustainable Development}

The concept of sustainable development and the three dimensions of sustainabilitysociety, economics and the environment-are attributed to the UN's 1987 Brundtland Commission Report. It called for "a new era of economic growth-growth that is forceful and the same time socially and environmentally sustainable," and it defined sustainable development as meeting "the needs of the present without compromising the ability of future generations to meet their own needs" [12]. The report describes society's desire to improve well-being now and society's responsibility to maintain environmental resources for future generations. Inter-generational equity and well-being, environmental resource maintenance, and trade-offs across the three dimensions underpin the definition. The three 
dimensions of sustainability continue to inform the SDGs, which are "integrated and indivisible and balance the three dimensions of sustainable development: the economic, social and environmental" [13]. While sustainability is achieved when the social, economic, and environmental dimensions are balanced or maximized with respect to the other two [14], limited guidance has been provided about how to achieve this goal [14,15].

\section{Toward a Definition of Sustainable Healthy Diets}

Healthy diets can be defined based on their capacity to meet nutrient needs, support growth and development, and reduce risk for non-communicable diseases [16-18]. Healthy dietary patterns, as identified in most national food-based dietary guidelines, are built around a variety of nutrient-dense foods and beverages, including plant- and animalsourced foods, while limiting foods containing excess fat, sugar and salt and foods of minimal nutritional value $[19,20]$.

Sustainable diets are defined by the Food and Agriculture Organization of the United Nations (FAO) as nutritionally adequate and healthy, safe, culturally acceptable, economically fair and affordable and having little environmental impact [21]. This definition adds human health to the social, economic and environmental dimensions. These four dimensions can be found in the sustainable diets literature $[16,22]$ as can new descriptions of sustainable healthy diets [23-25].

\section{Defining Sustainable Food Systems}

The FAO High Level Panel of Experts (HLPE) defines a food system to include "activities that relate to the production, processing, distribution, preparation and consumption of food, and the output of these activities, including socio-economic and environmental outcomes" [26]. The HLPE also succinctly defines a sustainable food system as one "that ensures food security and nutrition for all in such a way that the economic, social and environmental bases to generate food security and nutrition of future generations are not compromised" [16]. The HLPE food system framework includes social equity of food access as the key social impact of diets [27]; it can improve food security and social equity overall [16].

In 2020, the HLPE described sustainable food systems in context of the UN's Right to Food and expanded the well-known four dimensions of food security [28] to six, with the addition of agency and sustainability [27]. In this context, a sustainable food system is defined as: "productive and prosperous (to ensure the availability of sufficient food); equitable and inclusive (to ensure access for all people to food and to livelihoods within that system); respectful and empowering (to ensure agency for all people and groups to make choices and exercise voice in shaping that system); resilient (to ensure stability in the face of shocks and crises); regenerative (to ensure sustainability in all its dimensions), and healthy and nutritious (to ensure nutrient uptake and utilization)" [27].

The addition of agency and sustainability as dimensions of food security and sustainability may provide research opportunities to build on social equity topics to address the broader concept of social well-being [29]. A framework to measure well-being and societal progress supported by extensive collaborative research is available [30,31]. These, and other frameworks and models, may be of value as food systems continue to evolve to achieve equitable and sustainable food security, nutrition and social well-being [32-34].

\section{Why Is There a Gap in Social Dimension Research?}

Much of the research on diets and sustainability has relied on health and environmental outcomes, with less attention given to social and economic dimensions [2,3]. The social dimension is also under-represented or poorly understood in literature on food systems [4-6], sustainable agriculture [7,8] and social sustainability [9-11]. Social sustainability scientists have suggested reasons for this gap. Multiple models have been used to explain how the three sustainability dimensions interact with each other, ranging from separate pillars to integrated systems $[11,15]$. In addition, there are many legitimate meanings of 
social sustainability, addressing social priorities that are diverse and context-specific [11]. Social sustainability includes both procedural aspects (the "how") and substantive aspects (the "what" or social goals) [10]. Finally, social sustainability may contribute to sustainable development research in three distinct ways, including "development sustainability," concerned with basic needs; "bridge sustainability," concerned with behavior change to meet environmental goals; and "maintenance sustainability," concerned with sociocultural responses to change [9].

\section{Social Dimension of Foods, Diets and Food Systems-Many Indicators, Limited Data}

The three main communities engaged in sustainable food systems literature are agriculture, nutrition and [socio]ecology [5]. Of these, the nutrition literature has been the least likely to mention or define sustainability [5]. When included, the concept of sustainability mainly refers to the environmental footprint of meat consumption as opposed to vegan diets [5]. The discipline of nutrition, however, is opening up to research on food systems. The new focus on food systems, nutrition and health $[16,35]$ provides new opportunities for nutrition science to engage more with the health, social, economic, and environmental dimensions of sustainable healthy diets. There will be further opportunities to pair human nutrition with sustainability science, and many entry points exist to a further study of food systems [36].

"Social" describes the functions of society and how individual members of society interact, and the social dimension of sustainability is relevant to our understanding of diets, food systems and food security and nutrition. In addition to social equity of food access and social well-being, examples of topics which can link to the social perspective in food systems research include food choice behaviors [37,38], food systems ethics [39], and socioecological systems [40]. The social dimension can be expanded to yield socio-economic and socio-cultural perspectives and indicators. Food systems can also be viewed in terms of the social science disciplines at play where decision-making and action occur [41]. At global levels, for example, political science and international relations will be influential, while at the local/community level, sociology, economics, and anthropology will predominate [41].

Composite scores are of interest for ranking the sustainability of food systems using multiple dimensions. When it comes to the social domain, only a small group of socioeconomic indicators have been used, despite the many possible indicators available [42]. Table 1. lists socioeconomic indicators used in developing sustainability scores $[3,4,6,43]$.

Table 1. Indicators to measure socioeconomic dimensions in select multi-dimensional composite scores developed to rank overall food system sustainability.

\begin{tabular}{|c|c|c|c|}
\hline $\begin{array}{l}\text { Socioeconomic } \\
\text { Indicators [3] }\end{array}$ & $\begin{array}{c}\text { Social } \\
\text { Indicators [4] }\end{array}$ & $\begin{array}{l}\text { Socioeconomic } \\
\text { Indicators [6] }\end{array}$ & $\begin{array}{l}\text { Sociocultural Well-being } \\
\text { Indicators [43] }\end{array}$ \\
\hline $\begin{array}{l}\text { Income } \\
\text { Wealth } \\
\text { Equity }\end{array}$ & $\begin{array}{c}\text { Gender/equity } \\
\text { Inclusion } \\
\text { Labor force } \\
\text { participation, female }\end{array}$ & $\begin{array}{c}\text { Food security } \\
\text { Food affordability } \\
\text { Food availability } \\
\text { Food utilization } \\
\text { Socioeconomic welfare } \\
\text { Animal health and welfare }\end{array}$ & $\begin{array}{l}\text { Gender equity } \\
\text { Extent of child labor } \\
\text { Respect for community rights } \\
\text { Animal health and welfare }\end{array}$ \\
\hline
\end{tabular}

As an example, one composite sustainability score published in 2019 proposed 20 separate indicators across four dimensions, yet only one indicator was social and one was economic, and neither one covered food systems comprehensively [4]. Researchers indicated that more national level data associated with "social and economic dynamics" of food systems would increase the number of indicators applicable across countries [4]. Thus, filling knowledge gaps on the social and economic dimensions to help meet society's food security and nutrition needs affordably, equitably and sustainably is a priority. 


\section{Sustainable Healthy Diets: Approaches and Indicators}

Diet quality can be improved by increasing the proportion of nutrient-dense foods within energy adequate diets. Nutrition security requires both nutrients and calories. Though the world has been successful at producing adequate calories from staple foods, the more nutrient-rich foods are not routinely available or affordable for all populations [44] Global priorities for achieving sustainable food security increasingly focus on improving access to affordable nutrient density for all [44]. Improving diet quality will reduce food insecurity and hunger and address the triple burden of malnutrition $[44,45]$.

Research on improving access to sustainable healthy diets has shown that some tradeoffs across the four dimensions of sustainability may need to be made. Nutritionally optimal diets are not always affordable or may not have the lowest environmental footprint [46]. Lower-cost diets that are culturally acceptable may provide ample calories but insufficient nutrients [44]. These inherent tensions and trade-offs require the development of high-quality indicators for assessing the social aspects of sustainable healthy diets [46].

Animal-sourced foods, in particular, are examples of sustainability trade-offs [5]. Animal-sourced foods are nutrient-rich foods that are featured in food-based dietary guidelines globally. Yet livestock produce methane and farm management has implications for water, land and energy use. Along the social domain and from a global perspective, it is important to note that livestock generate income and represent other important social, cultural and economic values and resources, especially in low- and middle- income countries (LMIC) [47]. Given that healthy diets are not necessarily the most sustainable (in the sense of environmental impact) [46,48], context-specific communications will be needed to convey the importance of sustainable healthy diets to the global consumer $[48,49]$.

Whether diets are perceived as sustainable often depends on the environmental sustainability of agricultural practices, which vary significantly in different regions of the world. Assessment tools to track on-farm agricultural sustainability lack agreement about what should be assessed, "especially" for the social dimension [7]. Sustainable agricultural intensification is part of SDG 2 and 15; sustainable intensification (SI) "comprises agricultural processes or systems in which production is maintained or increased while progressing toward substantial enhancement of environmental outcomes," including positive social and economic outcomes [50]. SI is broadly applicable, "emphasizing outcomes rather than means, applying to any size of enterprise, and not predetermining technologies, production type, or particular design components" [51]. Social capital, which increases "trust, reciprocity and mutual obligations, and creates norms that guide behaviors" [50], can improve collective action for agricultural sustainability. Social capital has been associated with successful redesign of agroecosystems at geographic scale [50], farm resilience [52], food security among smallholder farmers [53], and it may support agricultural innovation [54].

Determining whether a diet is more, or less, sustainable is complex. The food systems approach, including drivers, outcomes and feedbacks, provides a better frame than following a "global" definition of a sustainable diet. The implications of achieving dietary shifts to increase health and sustainability are significant, from scientific and societal perspectives, especially when all dimensions of sustainability cannot be achieved to the same extent and at the same time. Sustainability criteria for making choices due to trade-offs not only depend on "scientific or practical considerations, but also on norms and moral values" [55], reinforcing the value of holistically accounting for all four dimensions of sustainability.

\section{Socioeconomic Indicators: Affordable Nutrient Density}

Since 2001, FAO's definition of food security has included social, physical and economic access [56]. Diet quality worsens with constraints on food access [44], and high relative prices for nutrient-dense foods and diets, compared to nutrient-poor, energy-dense foods, are linked to hidden hunger, malnutrition, and obesity across the socioeconomic gradient [57]. Relative food prices partially explain international differences in the prevalence of undernutrition and overweight [58]. Food access and the relative affordability of foods is also shaped by social factors such as wages, incomes, housing, child-care, and 
transportation [59]. Coordinated efforts to lower food prices, increase nutrition assistance, and increase income can improve food access. Integrating multiple socioeconomic perspectives to improve access to affordable, nutrient-dense foods can help improve food security and social well-being.

\section{The Need for Sociocultural Indicators}

Culture can be a "major influence" on food choice which can be influenced by gender, religion, cultural prohibitions, beliefs and attitudes [60]. Cultural food habits are learned early in life and can be modified by exposure to new food environments, media, peers [61] and sociodemographic factors $[57,60]$. Culturally-acceptable food habits may not produce diets that are healthy or sustainable [46,48], and culturally-acceptable foods may differ considerably among certain individuals or groups. Accepting cultural food habits reflects the value of inclusiveness in food systems, yet questions have been raised about the meaning of culture with respect to food system sustainability [5].

As food systems change to accommodate shifting demographics, livelihoods, roles of women, and social norms and traditions, better understanding about how sociocultural beliefs and habits can help or hinder food system transformation will be of value. More research is needed, for example, about how food acceptability [46] or sustainability awareness [62] influence food choice, and how to develop culturally-specific frameworks to support dietary change [63]. The value of the sociocultural perspective is captured in the concept of territorial diets, an approach to improve food security using tailored, placebased solutions that account for economic, social and cultural diversity [64]. Ethnographies can promote learning about people and their cultures in this context.

\section{The Social Dimension: From Understanding to Action}

Studies on sustainability science and climate change have made a compelling case for increased contributions from the social sciences $[65,66]$. As the priorities move from "understanding to action," the big challenges involve "culture, society, behavior, and institutions," yet the social and human dimensions are under-represented in favor of the natural sciences, and "holistic integrated research" is not the norm [65]. Social science perspectives can contribute insight about how behavior, culture, and experience complement systems science; understanding across individual, local and global scales; and experience about integrative research methods [65]. The social dimension can also be a relevant frame to help researchers and practitioners communicate, make decisions, assess outcomes and recognize how different perspectives may complement each other [10,11,67].

Contributions from social science can help address emerging food system priorities such as managing trade-offs in an equitable way $[5,55]$ and transformation to more sustainable food systems. The transformation process will need to facilitate and coordinate systems change that includes society at large. This process will need a multi-dimensional sustainability framework relevant in multiple contexts [5]; supporting processes to (re)frame norms, values, and behaviors that support health and sustainability [68]; transformation through innovation, which "will require building trust, changing mindsets, enabling social license, developing transition pathways and safeguarding against undesirable effects" [69]; and helping the sectors of society at risk of being left behind during transformations [69]. Many researchers have recommended transdisciplinary research — "science with society" - to help study and bridge science and society to solve complex sustainability problems [22,70-72].

\section{Research Is Needed to Integrate the Social Dimension}

Many opportunities exist for the nutrition community to research sustainable food system topics while integrating social dimension concepts, methods and indicators. Five main opportunities are listed below:

1. Study the social and economic dynamics in low-, middle- and high-income countries and to build data for use in food systems models 
2. Build knowledge about food systems connectivity across health, social, economic and environmental dimensions that enhances access to affordable, high-quality diets

3. Increase use of participatory, multidisciplinary and transdisciplinary research to integrate the social and natural sciences into food system solutions

4. Build knowledge about socially equitable food systems trade-offs and transformations

5. Leverage social perspectives to help researchers and practitioners make decisions, assess outcomes and improve appreciation of different viewpoints

\section{Conclusions}

Including sociocultural indicators to better understand food systems interactions will fill a major research gap because the social dimension is critical to the new concepts of social equity, equitable livelihoods and cultural inclusion as they apply to food system transformation. Affordable nutrient density is the current focus to achieve sustainable food security and nutrition. Each of the four dimensions has indicators that can be used to create models, yet the use of social indicators has been limited. Attention to the social dimension is the only way to ensure that sustainable healthy diets are tailored to the needs of specific population as opposed to a single dietary benchmark for all. The 2021 United Nations Food Systems Summit may be an opportunity to bring attention to this topic. Filling this gap will enhance our ability to meet society's food security and nutrition needs affordably, equitably and sustainably.

Author Contributions: Conceptualization, J.N. and A.D.; writing—original draft preparation J.N.; writing - review and editing, J.N. and A.D. All authors have read and agreed to the published version of the manuscript.

Funding: This research received no external funding.

Institutional Review Board Statement: Not applicable.

Informed Consent Statement: Not applicable.

Data Availability Statement: Not applicable.

Acknowledgments: The authors would like to acknowledge Jean-Michel Couture, and Bertrand Montel, of Groupe AGÉCO, Montreal, Canada, for their invaluable insights about the social dimension of sustainable diets.

Conflicts of Interest: A.D. has received grants, contacts, and honoraria from public agencies, nonprofit organizations, and private entities with an interest in nutrient profiling and in assessing the nutrient density of food patterns and the total diet. J.N. declares no conflict of interest.

\section{References}

1. Blackstone, N.T.; El-Abbadi, N.H.; McCabe, M.S.; Griffin, T.S.; E Nelson, M. Linking sustainability to the healthy eating patterns of the Dietary Guidelines for Americans: A modelling study. Lancet Planet. Health 2018, 2, 344-352. [CrossRef]

2. Jones, A.D.; Hoey, L.; Blesh, L.; Miller, L.; Green, A.; Shapiro, L.F. A systematic review of the measurement of sustainable diets. Adv. Nutr. 2016, 7, 641-664. [CrossRef]

3. Eme, P.E.; Douwes, J.; Kim, N.; Foliaki, S.; Burlingame, B. Review of methodologies for accessing sustainable diets and potential for development of harmonized indicators. Int. J. Environ. Res. Public Health 2019, 16, 1184. [CrossRef] [PubMed]

4. Béné, C.; Prager, S.; Achicanoy, H.A.E.; Alvarez Toro, P.; Lamotte, L.; Bonilla, C.; Mapes, B. Global map and indicators of food system sustainability. Sci. Data 2019, 6, 279. [CrossRef]

5. Béné, C.; Oosterveer, P.; Lamotte, L.; Brouwer, I.D.; de Haan, S.; Prager, S.D.; Talsma, E.F.; Khoury, C.K. When food systems meet sustainability-current narratives and implications for actions. World Dev. 2019, 113, 116-130. [CrossRef]

6. Melesse, M.B.; van den Berg, M.; Béné, C.; de Brauw, A.; Brouwer, I.D. Metrics to analyze and improve diets through food systems in low- and middle-income countries. Food Secur. 2020, 12, 1085-1105. [CrossRef]

7. Janker, J.; Mann, S. Understanding the social dimension of sustainability in agriculture: A critical review of sustainability assessment tools. Environ. Dev. Sustain. 2020, 22, 1671-1691. [CrossRef]

8. Struik, P.C.; Kuyper, T.W. Sustainable intensification in agriculture: The richer shade of green: A review. Agron. Sustain. Dev. 2017, 37, 39. [CrossRef]

9. Vallance, S.; Perkins, H.C.; Dixon, J.E. What is social sustainability? A clarification of concepts. Geoforum 2011, 8, 342-348. [CrossRef] 
10. Boström, M. A missing pillar? Challenges in theorizing and practicing social sustainability: Introduction to the special issue. Sustain. Sci. Pract. Policy 2012, 8, 3-14. [CrossRef]

11. Boyer, R.H.W.; Peterson, N.D.; Arora, P.; Caldwell, K. Five approaches to social sustainability and an integrated way forward. Sustainability 2016, 8, 878. [CrossRef]

12. Bruntland, G.H.; World Commission on Environment and Development. Our Common Future; Oxford University Press: New York, NY, USA, 1987.

13. UN General Assembly. Transforming Our World: The 2030 Agenda for Sustainable Development; UN: New York, NY, USA, 2015.

14. Barbier, E.B.; Burgess, J.C. The sustainable development goals and the systems approach to sustainability. Economics 2017, 11, 1-23. [CrossRef]

15. Purvis, B.; Mao, Y.; Robinson, D. Three pillars of sustainability: In search of conceptual orgins. Sustain. Sci. 2019, 14, 681-695. [CrossRef]

16. HLPE. Nutrition and Food Systems: A Report by the High Level Panel of Experts on Food Security and Nutrition of the Committee on Food Security; HLPE: Rome, Italy, 2017.

17. WHO. Healthy Diets Fact Sheet, No. 394. Available online: http://www.who.int/mediacentre/factsheets/fs394/en/ (accessed on 27 May 2021).

18. U.S. Department of Agriculture; U.S. Department of Health and Human Services. Dietary Guidelines for Americans, 2020-2025, 9th ed.; USDA: Washington, DC, USA, 2020.

19. Herforth, A.; Arimond, M.; Alvarez-Sanchez, C.; Coates, J.; Christianson, K.; Muehlhoff, E. A global review of food-based dietary guidelines. Adv. Nutr. 2019, 10, 590-605. [CrossRef] [PubMed]

20. Global Nutrition Report. 2020 Global Nutrition Report. Available online: https://globalnutritionreport.org/reporst/2020-globalnutrition-report (accessed on 7 May 2021).

21. Burlingame, B.; Dernini, S. Sustainable diets and biodiversity: Directions and solutions for policy, research and action. In International Scientific Symposium; FAO Headquarters: Rome, Italy, 2010.

22. Drewnowski, A. The Chicago consensus on sustainable food systems science. Front. Nutr. 2018, 4, 74. [CrossRef]

23. FAO; WHO. Sustainable Healthy Diets_Guiding Principles; FAO; WHO: Rome, Italy, 2019.

24. Macdiarmid, J.; Kyle, J.; Horgan, G.; Loe, L.; Fyfe, C.; Johnston, A.; McNeill, G. Livewell—A Balance of Healthy and Sustainable Food Choices; WWF-UK: Godalming, UK, 2011.

25. Mason, P.; Lang, T. Sustainable Diets: How Ecological Nutrition Can Transform Consumption and the Food System; Routledge: London, UK, 2017. [CrossRef]

26. HLPE. Food Losses and Waste in the Context of Sustainable Food Systems: A Report by the High Level Panel of Experts on Food Security and Nutrition of the Committee on World Food Security; HLPE: Rome, Italy, 2014.

27. HLPE. Food Security and Nutrition: Building a Global Narrative towards 2030: A Report by the High Level Panel of Security and Nutrition of the Committee on World Food Security; HLPE: Rome, Italy, 2020.

28. Jones, A.D.; Ngure, F.M.; Pelto, G.; Young, S.L. What are we assessing when we measure food security? A compendium and review of current metrics. Adv. Nutr. 2013, 4, 481-505. [CrossRef]

29. Sen, A. Well-being, agency and freedom: The Dewey lectures, 1984. J. Philos. 1985, 82, 169-221. [CrossRef]

30. Stiglitz, J.E.; Sen, A.; Fitoussi, J.P. The Measurement of Economic Performance and Social Progress Revisited Reflections and Overview; Sciences Po Publications: Paris, France, 2009.

31. Measuring Well-Being and Progress: Well-Being Research-OECD. Available online: https://www.oecd.org/statistics/measuringwell-being-and-progress.htm (accessed on 7 May 2021).

32. OECD. Making Better Policies for Food Systems; OECD Publishing: Paris, France, 2021. [CrossRef]

33. FAO. Vision and Strategy for FAO's Work in Nutrition; FAO: Rome, Italy, 2021.

34. Dury, S.; Bendjebbar, P.; Hainzelin, E.; Giordano, T.; Bricas, N. (Eds.) Food Systems at Risk: New Trends and Challenges; FAO: Rome, Italy; European Commission: Montpellier, France; CIRAD: Brussels, Belgium, 2019. [CrossRef]

35. Fanzo, J.; Bellows, A.L.; Spiker, M.L.; Thorne-Lyman, A.L.; Bloem, M.W. The importance of food systems and the environment for nutrition. Am. J. Clin. Nutr. 2021, 113. [CrossRef]

36. Spiker, M.L.; Knoblock-Hahn, A.; Brown, K.; Giddens, J.; Hege, A.S.; Sauer, K.; Enos, D.M.; Steiber, A. Cultivating sustainable, resilient, and healthy food and water systems: A nutrition-focused framework for action. J. Acad. Nutr. Diet. 2020, 120, 1057-1067. [CrossRef] [PubMed]

37. Marcone, M.F.; Madan, P.; Grodzinski, B. An overview of the sociological and environmental factors influencing eating food behavior in Canada. Front. Nutr. 2020, 7, 77. [CrossRef]

38. Contento, I. Overview choice and dietary change: Implications for nutrition education. In Nutrition Education: Linking Research Theory and Practice, 2nd ed.; Contento, I., Ed.; Jones \& Bartlett Learning: Sudbury, MA, USA, 2011; pp. $26-42$.

39. Fanzo, J. Healthy and sustainable diets and food systems: The key to achieving sustainable development goal 2? Food Ethics 2019, 4, 159-174. [CrossRef]

40. Allen, T.; Prosperi, P. Modeling sustainable food systems. Environ. Manag. 2016, 57, 956-975. [CrossRef]

41. Uphoff, N. Systems thinking on intensification and sustainability: Systems boundaries, processes and dimensions. Curr. Opin. Environ. Sustain. 2014, 8, 89-100. [CrossRef] 
42. Comerford, K.; Arndt, C.; Drewnowski, A.; Ericksen, P.; Griffin, T.; Hendrickson, M.; Ingram, J.; Nicholls, J. Proceedings of a workshop on characterizing and defining the social and economic domains of sustainable diets. Sustainability 2020, $12,4163$. [CrossRef]

43. Chaudhary, A.; Gustafson, D.; Mathys, A. Multi-indicator sustainability assessment of global food systems. Nat. Commun. 2018, 9, 848. [CrossRef] [PubMed]

44. FAO; IFAD; UNICEF; WFP; WHO. The State of Food Security and Nutrition in the World 2020; FAO: Rome, Italy, 2020. [CrossRef]

45. Global Panel on Agriculture and Food Systems for Nutrition. Improving Nutrition through Enhanced Food Environments. London, UK, 2016. Available online: https://glopan.org/sites/default/files/FoodEnvironmentsBrief.pdf (accessed on 27 May 2021).

46. Perignon, M.; Vieux, F.; Soler, L.G.; Masset, G.; Darmon, N. Improving diet sustainability through evolution of food choices: Review of epidemiological studies on the environmental impact of diets. Nutr. Rev. 2017, 75, 2-17. [CrossRef]

47. HLPE. Sustainable Agricultural Development for Food Security and Nutrition: What Roles for Livestock? A Report by the High Level Panel of Experts on Food Security and Nutrition of the Committee on World Food Security; HLPE: Rome, Italy, 2016.

48. MacDiarmid, J.I. Is a healthy diet an environmentally sustainable diet? Proc. Nutr. Soc. 2013, 72, 13-20. [CrossRef] [PubMed]

49. European Commission. Communication from the Commission to the European Parliament, the Council, the European Economic and Social Committee and the Committee of the Regions. A Farm to Fork Strategy for a Fair, Healthy and Environmentally-Friendly Food System; EU: Brussels, Belgium, 2020.

50. Pretty, J. Intensification for redesigned and sustainable agricultural systems. Science 2018, 362, aav0294. [CrossRef] [PubMed]

51. Pretty, J.; Benton, T.; Bharucha, Z.P.; Dicks, L.V.; Flora, C.B.; Godfray, H.C.J.; Goulson, D.; Hartley, S.; Lampkin, N.; Morris, C.; et al. Global assessment of agricultural system redesign for sustainable intensification. Nat. Sustain. 2018, 1, 441-446. [CrossRef]

52. OECD. Strengthening Agricultural Resilience in the Face of Multiple Risks; OECD Publishing: Paris, France, 2020.

53. Niles, M.T.; Rudnick, J.; Lubell, M.; Cramer, L. Household and community social capital links to smallholder food security. Front. Sustain. Food Syst. 2021, 5, 44. [CrossRef]

54. Pretty, J. New opportunities for the redesign of agricultural and food systems. Agric. Hum. Values 2020, 37, 629-630. [CrossRef] [PubMed]

55. Struik, P.C.; Kuyper, T.W. Editorial overview: Sustainable intensification to feed the world: Concepts, technologies and trade-offs. Curr. Opin. Environ. Sustain. 2014, 8, vi-viii. [CrossRef]

56. FAO. The State of Food Insecurity in the World 2001; FAO: Rome, Italy, 2001; Available online: http://www.fao.org/3/y1500e/y150 0e02.htm (accessed on 27 May 2021).

57. Darmon, N.; Drewnowski, A. Contribution of food prices and diet cost to socioeconomic disparities in diet quality and health: A systematic review and analysis. Nutr. Rev. 2015, 73, 643-660. [CrossRef] [PubMed]

58. Headey, D.D.; Alderman, H.H. The relative caloric prices of healthy and unhealthy foods differ systematically across income levels and continents. J. Nutr. 2019, 149, 2020-2033. [CrossRef] [PubMed]

59. Hirvonen, K.; Bai, Y.; Headey, D.; Masters, W.A. Affordability of the EAT-Lancet reference diet: A global analysis. Lancet Glob. Health 2020, 8, e59-e66. [CrossRef]

60. Cox, D.N.; Anderson, A.S. Food choice. In Public Health Nutrition; Gibney, M.J., Margetts, B.M., Kearney, J.M., Arab, L., Eds.; Blackwell Science: Oxford, UK, 2004; pp. 144-166.

61. Chard, S.; Roth, E.G. Food Culture, Society. In Introduction to the U.S. Food System: Public Health, Environment, and Equity; Neff, R.A., Ed.; Jossey-Bass: San Francisco, CA, USA, 2015; pp. 215-236.

62. Rejman, K.; Kaczorowska, J.; Halicka, E.; Laskowski, W. Do Europeans consider sustainability when making food choices? A survey of Polish city-dwellers. Public Health Nutr. 2019, 22, 1330-1339. [CrossRef] [PubMed]

63. Mayton, H.; Beal, T.; Rubin, J.; Sanchez, A.; Heller, M.; Hoey, L.; de Haan, S.; Duong, T.; Huynh, T.; Burra, D.; et al. Conceptualizing sustainable diets in Vietnam: Minimum metrics and potential leverage points. Food Policy 2020, 91. [CrossRef]

64. OECD; FAO; UNCDF. Adopting a Territorial Approach to Food Security and Nutrition Policy; OECD Publishing: Paris, France, 2016.

65. Shrivastava, P.; Stafford Smith, M.; O’Brien, K.; Zsolani, L. Transforming sustainability science to generate positive social and environmental change globally. One Earth 2020, 2, 329-340. [CrossRef] [PubMed]

66. ISCC; UNESCO. The World Social Science Report 2013: Changing Global Environments; OECD Publishing: Paris, France, 2013.

67. Velten, S.; Leventon, J.; Jager, N.; Newig, J. What is sustainable agriculture? A systematic review. Sustainability 2015, 7, 7833-7865. [CrossRef]

68. Nyborg, K.; Anderies, J.M.; Dannenberg, A.; Lindahl, T.; Schill, C.; Schlüter, M.; Adger, W.N.; Arrow, K.J.; Barrett, S.; Carpenter, S.; et al. Social norms as solutions. Science 2016, 354, 42-43. [CrossRef]

69. Herrero, M.; Thorton, P.K.; Mason-D'Croz, D.; Palmer, J.; Benton, T.G.; Bodirsky, B.L.; Bogard, J.R.; Hall, A.; Lee, B.; Nyborg, K.; et al. Innovation can accelerate the transition towards a sustainable food system. Nat. Food 2020, 1, 266-272. [CrossRef]

70. Hammond, R.A.; Dube, L. A systems science perspective and transdisciplinary models for food and nutrition security. Proc. Natl. Acad. Sci. USA 2012, 109, 12356-12363. [CrossRef] [PubMed] 
71. Lang, D.J.; Wiek, A.; Bergmann, M.; Stauffacher, M.; Martens, P.; Moll, P.; Swilling, M.; Thomas, C. Transdisciplinary research in sustainability science: Practice, principles, and challenges. Sustain. Sci. 2012, 7, 25-43. [CrossRef]

72. Stegar, C.; Klein, J.A.; Reid, R.S.; Lavorel, S.; Tucker, C.; Hopping, K.A.; Marchant, R.; Teel, T.; Cuni-Sanchez, A.; Dorji, T.; et al. Science with society: Evidence-based guidance for best practices in environmental transdisciplinary work. Glob. Environ. Chang. 2021, 68, 102240. [CrossRef] 